\title{
Qualidade da Educação Infantil: avaliação em rede e monitoramento regional - Entrevista com Antonio Gariboldi ${ }^{1}$
}

\section{Quality of Early Childhood Education: network evaluation and regional monitoring - Interview with Antonio Gariboldi}

\author{
Catarina Moro*
}

\begin{abstract}
RESUMO
Nesta entrevista, Antonio Gariboldi, pesquisador e professor italiano da Università Degli Studi di Modena e Reggio Emilia, na Emilia Romagna, expõe suas pesquisas e relata a assessoria que prestou para redes italianas, municipais e regionais de educação. Seu trabalho é centrado na avaliação e se desenvolveu a partir da criação de um sistema regional de monitoramento de qualidade educativa dos serviços para a primeira infância e da organização de contextos educativos. Gariboldi fala, também, sobre atividades formativas, muitas vezes, realizadas na forma de pesquisa-ação. Sou muito grata à mediação inicial da pesquisadora Donatella Savio, da Università Degli di Studi di Pavia, que possibilitou meu encontro com o Professor Antonio Gariboldi, no período que estive na Itália para pós-doutoramento. Também agradeço ao professor pela atenção e recepção desde os primeiros contatos até o encontro presencial nas dependências da UNIMORE em Reggio Emilia.
\end{abstract}

Palavras-chave: Educação Infantil. Qualidade. Avaliação. Monitoramento em rede.

1 A entrevista em questão foi parte das atividades do estágio pós-doutoral realizado junto à Università degli Studi di Pavia, na Itália, entre 2015 e 2016. O estágio foi financiado com bolsa PDE pela CAPES.

* Universidade Federal do Paraná. Curitiba, Paraná, Brasil. E-mail: moro.catarina@gmail. com. https://orcid.org/0000-0003-3109-5885 


\begin{abstract}
In this interview, Antonio Gariboldi, an Italian researcher and professor at the Università Degli Studi di Modena e Reggio Emilia in Emilia Romagna, presents his research and reports the advisory he provided to Italian, municipal and regional education networks. His work is centered in the evaluation and it was developed from the creation of a regional system for monitoring of educational quality of the services for the infancy and the organization of educative contexts. Gariboldi also speaks about formative activities, often carried out in the form of action research. I am very grateful for the initial mediation of the researcher Donatella Savio, from the Università Degli di Studi di Pavia, who made my meeting with Professor Antonio Gariboldi possible, in the period I was in Italy for postdoctoral studies. I also thank the teacher for the attention and reception from the first contacts to the faceto-face meeting at the UNIMORE premises in Reggio Emilia.
\end{abstract}

Keywords: Early Childhood Education. Quality. Evaluation. Network Monitoring.

\title{
FIGURA 1 - GABINETE DO PROF. ANTONIO GARIBOLDI, NA UNIMORE. NA FOTOGRAFIA, ENTREVISTADO E ENTREVISTADORA
}

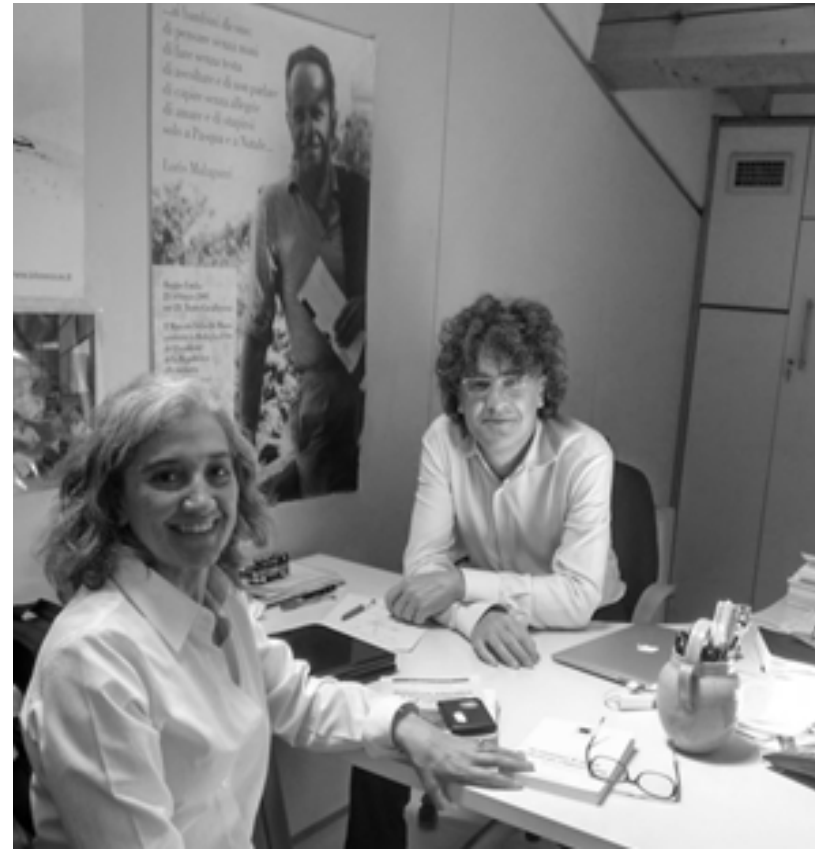

FONTE: Arquivo pessoal. 
Antonio Gariboldi (A. G.) graduou-se em Filosofia na Università degli Studi di Pavia e, em 1996, doutorou-se em Pedagogia Experimental pela Università degli Studi di Roma com a tese sobre "Modelos de 'pedagogia latente' na pré-escola". Atuou em diferentes projetos de pesquisa desde o início dos anos de 1990, tendo trabalhado com Egle Becchi, Anna Bondioli, Roberta Cardarello, Luciano Cecconi, Umberto Margiotta. Entre os projetos mais recentes estão o Creanet: Creativity in pre-school education, financiado no bojo do programa Comenius, que reuniu diversos países europeus e o Progetto RIQUA - Riflessione Qualità, de pesquisa-formação sobre avaliação da qualidade educativa em escolas infantis da Federazione Italiana Scuole Materne (FISM) de Bologna. Desde 1993 suas atividades de pesquisa são acompanhadas de atividades formativas de aperfeiçoamento dos profissionais de instituições educativas para a pequena infância.

Entre os anos de 2004 e 2007, Gariboldi participou da Comissão para organização e realização de cursos de especialização para qualificação de pessoal para a atuação em pré-escola e escola primária (correlata do Ensino Fundamental, no caso do Brasil). Foi responsável didático (2007/2008) pelo Mestrado Internacional em "Coordenação Pedagógica em Serviços Educativos para a primeira infância", organizado na UNIMORE em colaboração com Reggio Children e com pré-escolas e creches do município de Reggio Emilia. Nesse curso, ministrou o módulo "Abordagens e instrumentos de avaliação da qualidade educativa". No curso de graduação em Ciência da Educação na UNIMORE foi responsável pelas disciplinas: "Progettazione e valutazione dei contesti educativi prescolari"; "Metodologia del gioco e della creatività". E "Valutazione della qualità degli organismi educativi e formativi" junto ao curso de Ciência Pedagógica.

Em fevereiro de 2013, o professor Gariboldi participou do Seminario Internazionale "La qualità dei servizi educativi per l'infanzia in Italia e in Brasile: orientamenti politici ed esperienze di valutazione" promovido pelas professoras Anna Bondioli e Donatella Savio (Università Degli Studi d Pavia) em parceria com as professoras Gizele de Souza e Catarina Moro (Universidade Federal do Paraná). Entre 2009 e 2015, foi consultor científico da Região da Emilia Romagna no projeto de elaboração e experimentação do sistema de avaliação da qualidade dos serviços educativos para a primeira infância. Participou, em 2017, do Comitê Científico da European Early Childhood Education Research Association (EECERA) para a realização da $27^{\text {th }}$ Conference - Early Childhood Education - Beyond the Crisis, em Bologna, na Itália. É membro de comitês de coleções como a "Bambini al centro", dirigida por Donatella Savio (Università Degli Studi di Pavia) - e "Culture e saperi dell'infanzia", dirigida por Massimo 
Baldacci (Università Degli Studi di Urbino), Franco Frabboni (Università Degli Studi di Bologna), Miguel Zabalza (Universidade de Santiago de Compostela).

C. M. Considerando sua trajetória de trabalho, há quanto tempo você está envolvido em projetos de pesquisa e de assessoramento que envolvem processos de avaliação da qualidade em serviços de educação infantil?

A. G. Poderia dizer que sempre, desde a época da minha tese de Doutorado, mais de vinte anos atrás. Atuei como formador por muitos anos, primeiro em uma lógica universitária quando cursava o Doutorado, depois, sem estar vinculado a nenhuma universidade, atuei como formador. Trabalhei muito em avaliação da qualidade de oferta educativa em instituições para crianças de 0 a 3 nos e de 3 a 6 anos. Ou seja, para toda a faixa de 0 a 6 anos, em diferentes realidades italianas. Após ingressar na Universidade (UNIMORE), este trabalho se constituiu como projetos, sempre de pesquisa e formação.

C.M. De onde partem as demandas de ações formativas e de assessoramento?

A. G. Em geral, é um pedido que vem dos municípios ou organizações, ou seja, não só dos municípios, porque eu também trabalhei para instituições privadas, como a Federazione Italiana Scuole Materne (FISM), que agrega instituições religiosas de educação e cuidados infantis, de orientação católica. Eu não tenho esse tipo de orientação, ou seja, podemos dizer que a questão era trabalhar com vários organismos que gerem os serviços educacionais para a infância a em nível local, por isso às vezes estas realidades são aquelas que têm mais problemas do ponto de vista da qualidade educacional. Do meu ponto de vista, foi importante construir essa colaboração, pois agora, na Itália, o sistema comporta instituições de caráter misto, público ou privado. Estive envolvido em um trabalho que durou vários anos e terminou recentemente, com a FISM de Bologna. Nessa região, a Federação é constituída de serviços (instituições) com abordagens pedagógicas variadas, as coordenadoras e coordenadores pedagógicos, contudo, estão muito à frente em comparação com a abordagem tradicional que caracteriza algumas FISM de outras regiões.

C.M. A demanda por assessoramento de instituições mantidas pela FISM poderia sugerir uma intenção? Ou seja, essa demanda sugere expectativa ou predisposição de mudança?

A. G. No caso da FISM de Bologna, houve uma busca por mudanças porque os pedagogos queriam trazer inovação para os serviços que consideravam tradicionais. Lá existe uma organização de trabalho com dois níveis de coordenação: uma coordenação pedagógica de cada instituição, que tem mais de 
uma função, com frequência é educadora, professora e também coordenadora. Tem um duplo papel. Há a coordenação da Federação, que não faz a gestão direta de uma unidade, mas indireta, ocupa-se da formação em nível da rede. Esse foi um grupo que viu a situação estática e queria trazer inovações, fez vários projetos desse ponto de vista. O projeto de avaliação de qualidade nasceu nesse sentido. Eu tive outra experiência, com a FISM de Modena, com a qual realizei vários percursos de avaliação de qualidade da pré-escola. Então, em algum momento, para construir um instrumento de avaliação, eles decidiram, escolher um formador de orientação católica que se articulava completamente com a abordagem deles. Na FISM de Bologna, a escolha foi diferente, pudemos continuar o trabalho, no qual buscamos a possibilidade de trabalhar sobre aspectos da pedagogia que representam elementos de qualidade mais transversais ao sistema de escolas e serviços daquela rede.

C. M. Considerando a vasta experiência com a avaliação da qualidade dos serviços educativos para a infância na Itália, especialmente em algumas regiões, podem-se identificar algumas mudanças, especialmente nos instrumentos e procedimentos que os diferentes processos utilizam?

A. G. Você encontrará na Itália, de forma mais geral, uma abordagem de avaliação que se refere a instrumentos estruturados e uma abordagem sistemática. Do meu ponto de vista, a relevância está mais no processo do que no instrumento. Mas, com referência ao uso dos instrumentos, cabe lembrar que no começo utilizávamos alguns norte-americanos, traduzidos e aplicados aos contextos italianos. Em seguida, foram construídos instrumentos ad hoc por pesquisadores universitários, que na última fase envolveram educadoras e professoras nessa elaboração, em uma lógica mais propriamente formativa. Este foi o caso de uma experiência na região da Emilia Romagna e, foi também o caso (que citei antes) da FISM de Modena, na qual por vários anos construímos juntos um instrumento. $\mathrm{O}$ interessante foi termos envolvido as coordenadoras de diversas unidades da FISM, de modo que a dimensão formativa foi ativada durante a construção do instrumento, porque eles estavam comprometidos na elaboração. Na verdade, eles consideraram o processo muito formativo, porque no nível da rede, os coordenadores compartilharam conceitos, linguagens, visões, em seguida, começaram a trabalhar em uma ideia operacionalizável, compartilhada e explicitada de qualidade. Nesse sentido, as abordagens distintas estão relacionadas à valorização das dimensões formativas do processo, ou seja, valorizam, em alguma medida, o envolvimento; além disso, também a participação decisória das educadoras é colocada em primeiro plano. 
C. M. Poderia ser dito que fazer parte de um processo como este é uma forma de criar a participação no grupo?

A. G. Algumas vezes pode-se, de fato, construir a participação através deste processo dos grupos, porque coloca-se num grupo pessoas que, por vezes, ainda não são um, mas que estão tentando construir uma comunidade de práticas, no sentido de partilhar o repertório de ideias, de enunciados, de linguagens, através deste processo de construção compartilhada de uma ideia de qualidade, antes de mais nada.

C. M. Talvez fosse interessante retomar a narrativa acerca da experiência desenvolvida na região da Emilia Romagna. O fato de ser uma experiência de avaliação em rede, envolvendo todas as nove províncias (microrregiões) romanholas, encerra um valor muito significativo ao processo. Você pode contar um pouco sobre essa experiência?

A. G. Essa experiência decorre de um mandato político que estava ligado ao trabalho na direção do credenciamento das instituições, isso porque na lei $\mathrm{n}^{\mathrm{o}} 1$ de 2000, indicavam-se as normas de autorização para o funcionamento, seguido de trabalho nos anos seguintes; mas depois houve um artigo sobre credenciamento que nunca foi traduzido em uma diretriz.

C. M. A solicitação de credenciamento se aplicava tanto às instituições públicas; como às privadas?

A. G. O credenciamento é para as entidades privadas que querem ter acesso a fundos públicos e obrigatório para todos os entes públicos, então a ambição era construir um sistema de avaliação ligado ao credenciamento, mas não fosse de tipo certificativo, o que se constitui um desafio, um um tanto particular, no sentido de que, para nós, tinha que ser um plano que se relaciona com os elementos de qualidade estruturais; tais como a presença da coordenação pedagógica e as horas de formação para o grupo. Tais elementos podem ser objeto de uma avaliação para certificação, para então ser credenciado se possuir esses requisitos. Nossa ideia era de que deveria haver participação obrigatória em um sistema de avaliação formativa que tivesse como objeto de análise o contexto educacional e os processos educacionais. A ideia de que, nos processos educacionais, não posso intervir com uma lógica de padronização e com uma lógica de certificação.

C. M. No sentido, também, de não interromper o processo após a certificação, para fazer um processo contínuo.

A. G. Sim, pois a ideia é que a qualidade, antes de mais nada, mais que a adesão a um padrão, reside na capacidade de manter vivo um processo de pesquisa dentro das unidades educacionais. Depois em uma lógica transformadora, tendo, 
sobretudo, como grande tema a pluralidade de identidades educativas e, portanto, a tentativa de criar uma relação coerente, compartilhada entre alguns elementos compartilhados e distintos, na qual a diferença pode ser um valor, tendo como base alguns elementos comuns que representassem a expressão de uma cultura pedagógica, educativa que foi construída ao longo de vários anos na região da Emilia Romagna, então a tentativa era de construir essa base comum, deixando espaço para a diferença. O objetivo era este, o primeiro passo foi montar um grupo que trabalhasse na elaboração deste sistema de avaliação, um grupo formado pelos representantes dos coordenadores dos várias províncias ${ }^{2}$. Imediatamente, este grupo regional foi estabelecido, contando com todos os representantes das coordenações pedagógicas provinciais (na região emiliana são nove no total). No início, havia a preocupação de ter todas as coordenações provinciais ativas; pois havia uma coordenação que não funcionou durante anos, assim houve um forte impulso da região no nível político, para que se reconstituisse essa coordenação e se reativasse as funções para esta finalidade. As realidades são muito diferentes umas das outras, por exemplo, o contexto de Forli é bastante incomum. Cada realidade traz consigo suas questões e problemáticas específicas e, com isso, o trabalho que fizemos foi primeiro discutir um sumário do Projeto Pedagógico, que começou principalmente a partir do fato de que existiam creches, instituições que não tinham um projeto pedagógico, alguns tinham, outros não, alguns tinham um belo Projeto, outros tinham uma pequena página escrita e esta era o projeto pedagógico daquela creche. Assim, mesmo o compartilhamento de uma concepção do que é um Projeto Pedagógico, quais conteúdos devem constar de um projeto pedagógico, ainda que de forma mais geral, foi uma longa trajetória, para escrevermos poucas páginas foi um percurso de um ano e meio, que foi apenas o início da construção do grupo e impulsionamento do processo.

C. M. ... este momento inicial é um momento fundamental e desafiador para fomentar a participação de todas as pessoas e balizar valores e objetivos comuns...

A. G. ... sim e, inicialmente escrevemos as partes no âmbito do grupo regional, que foram então discutidas nas diferentes coordenações locais e

2 Na Itália, existe uma organização dos municípios em microrregiões dentro da região maior, chamadas de províncias. Na Emilia Romagna são 9 províncias - Piacenza, Parma, Reggio Emilia, Modena, Bologna, Ferrara, Ravenna, Forli-Cesena, Rimini -, cada uma variando entre 18, a menor, a 55 municípios, a maior província, respectivamente Ravenna e Bologna.

3 Sobre uma das experiências da província de Forli ver: MORO, Catarina. Diferentes olhares para a creche: a avaliação de contexto com o instrumento SPRING em um município da Emilia Romagna. Revista Linhas. Florianópolis, v. 19, n. 40, p. 138-160, maio/ago. 2018. Disponível em: http://dx.doi.org/10.5965/1984723819402018138 
então as observações realizadas-foram depois reportadas, no âmbito regional, e sistematizadas. Após esse processo, construímos um documento - que tem seus limites porque é também o fruto deste trabalho colaborativo de diferentes interlocutores -, compartilhado sobre uma ideia de um projeto pedagógico, que para nós é um passo fundamental. Com base nisso, pudemos começar a pensar sobre avaliação. Isto é, quando compartilhamos uma ideia de projeto pedagógico, algumas coordenadas sobre o projeto pedagógico, essas coordenadas servem de ponto de partida para se trabalhar no sistema de avaliação

C. M. Na ocasião do início deste processo de avaliação em rede já haviam sido realizadas outras experiências de avaliação na Emilia Romagna com a participação de pessoas que compunham o grupo regional de vocês?

A. G. Sim. Em alguns casos. Como a Cristina Stradi, que é uma coordenadora que trabalha há tempos na área e nessa função. Ela é da província de Modena e foi uma das primeiras a trazer a discusão sobre a avaliação... Agora está aposentada, lá. Também acompanhou atividades em Rimini, ultimamente como tutora. No entanto, mesmo antes, quando trabalhamos com a SVANI ${ }^{4}$ tivemos parceria com algumas pessoas que tinham muito conhecimento sobre avaliação, como Zanelli, que também estava nesse grupo. Paolo Anelli fez muitos trabalhos a respeito deste tema. E havia outros parceiros que ignoravam totalmente o tema. Isso também era um problema, considerarmos as expectativas daqueles que já estavam muito envolvidos com a questão e queriam conduzi-lo para níveis de discussão mais avançados e daqueles que começaram absolutamente do zero. Assim, posso dizer que este aspecto da mediação foi muito extenuante, entre outras coisas, este percurso foi introduzido a partir de um anterior, realizado no final dos anos de 1990 e que levou à publicação do livro "A qualidade negociada", organizado por Anna Bondioli. Naquele percurso, foram feitas diferentes experiências de avaliação com a SVANI e poderia afirmar que foi precursor, semeadura para os processos que se seguiram. Eu participei daquela jornada formativo-investigativa, e algumas realidades conheci dessa forma. Mas, no início do processo tivemos algumas realidades que nunca haviam lidado com avaliação e outras onde havia resistência a processos avaliativos, que em muitas situações era um dos problemas iniciais.

C. M. Essa resistência poderia ser atribuída também por persistir uma concepção de avaliação vinculada à ideia de estabelecimento de mérito, para

4 SVANI - Scala per la Valutazione Dell'Asilo Nido (Escala para avaliação da creche), traduzida de Infant/Toddler Enviroment Rating Scale (ITERS). 
averiguar se está de acordo ou não? Na Emilia Romagna essa seria uma concepção que ainda tem de ser enfrentada?

A. G. Este é um grande problema, a ideia de avaliação em uma perpectiva classificatória. Em muitos contextos educativos, a palavra avaliação evoca imediatamente uma visão negativa. Falamos muito de documentação, que implica uma perspectiva interpretativa, então trabalhar sobre indicadores é uma transição difícil e muito delicada para se experimentar. Devo lhe dizer, a exemplo, uma dificuldade que tivemos se relaciona a instituir a avaliação com base em dados empíricos, quanto à coleta de dados. Embora em nossos serviços tenha havido muitos cursos de formação sobre observação, na realidade, uma cultura de observação, de coleta de dados, para basear julgamentos em dados e não em impressões é algo que não se instituiu, não se generalizou. Assim, representa uma dificuldade, pois envolve também ter rigor, ter método. Mas, devo dizer que, de alguma forma, vivenciar um processo de avaliação da qualidade educativa permite um aprendizado de segundo nível. As repercussões não são apenas em referência à qualidade, ao trabalho sobre aspectos de qualidade que são o objeto de análise, mas também acerca de aprender uma maneira de trabalhar no interior dos próprios contextos.

C. M. Foi também uma formação importante sobre como ser educadora/ professora e pesquisar o próprio trabalho?

A. G. Diria que fizemos formação. Mas, repensando o percurso, não tínhamos informação suficiente em alguns momentos porque tínhamos o problema, de todo modo, de que não podíamos pedir demais aos coordenadores em termos de horas, já havíamos feito um primeiro curso de formação. Iniciamos este percurso fazendo um curso de formação para os coordenadores sobre alguns aspectos fundamentais do projeto pedagógico, da avaliação, mas, acima de tudo, houve uma partilha dos diferentes instrumentos e metodologias de avaliação que estiveram presentes na região de Emilia Romagna. Na fase inicial, havia coordenadores, gestores, de diferentes realidades que apresentaram, contaram aos demais o seu modo de fazer a avaliação, também a certificação ISO 9000, que é usada em várias Cooperativas de educação infantil, ou outros sistemas que foram desenvolvidos no mesmo período.

C. M. Quando este trabalho de avaliação em rede foi iniciado, existiam instrumentos avaliativos distintos entre si sendo utilizados?

A. G. Isso também foi um outro problema, pois obviamente, as realidades em que se investiu nessa temática tinham seus próprios instrumentos, por exemplo, em Parma, eles tinham o instrumento de Musatti (Tulia) e então havia também uma demanda por integrar esse instrumento e em qualquer caso não 
desprezar um certo tipo de trabalho sobre avaliação. Do nosso ponto de vista, nós construímos uma abordagem e algumas linhas de referência no que diz respeito à avaliação, indicadores, construção de instrumentos e procedimentos; mas, depois, cada coordenação pedagógica provincial teve um espaço de autonomia para construir o instrumento e adaptar os procedimentos. Assim, nós temos distintos instrumetos nas diferentes coordentações pedagógicas provinciais, que têm uma base comum, dada pelas Diretrizes sobre a avaliação do projeto pedagógico ${ }^{5}$.

C. M. De quando é este documento?

A. G. Tais diretrizes foram publicadas em 2012 e logo em seguida elas foram consideradas para proceder o monitoramento da qualidade, já tinha havido uma fase prévia de experimentação de auto-heteroavaliação. Assim, procedemos a experimentação, com adaptações às diretrizes, esclarecimentos processuais e assim por diante, até que conseguimos que se realizasse a auto-heteroavaliação em pelo menos $10 \%$ dos serviços de todas as províncias. Por isso consideramos ter sido uma experimentação generalizada, após a qual nós fizemos um relatório final sobre a eficácia da formação e experimentação para a sustentabilidade do processo e, aqui, a coisa toda parou. Nesse ínterim, houve mudança de assessor, no âmbito político, e passou a não se ter mais a intenção de continuar com o credenciamento. No momento atual, essa ideia está voltando. Algumas coordenações locais estão realizando por conta própria, apesar de em nível regional o processo ter parado precisamente porque, no âmbito da política, está se reescrevendo a lei sobre serviços para crianças. Assim, está em questão o que irá acontecer com todo este sistema, se continuará em operação... em primeira hipótese, deveria funcionar apenas o sistema de autoavaliação, mas agora há uma demanda pela realização de uma heteroavaliação... existe ainda uma nova condição, em nível nacional, relativa à lei sobre a continuidade $0 \mathrm{a}$ 6 , discussão da qual as províncias foram afastadas. São questões que devem ajustar-se e ser revistas.

C. M. Por ocasião da efetivação do sistema regional de monitoramento de qualidade educativa dos serviços para a primeira infância, na região emiliana, como era a opção por uso de determinado instrumento de avaliação pelas províncias?

5 Diretrizes Experimentais para a Elaboração do Projeto Pedagógico e Metodologia de Avaliação em Serviços Educacionais para a Primeira Infância (tradução livre de Linee Guida Sperimentali per la Predisposizione del Progetto Pedagogico e della Metodologia di Valutazione nei Servizi Educativi per la Prima Infanzia). Disponível em: https://sociale.regione.emilia-romagna. it/documentazione/norme/delibere/2012/NUOVA_DIRETTIVA.pdf. 
A. G. Somos nove (9) províncias e, agora, temos nove (9) instrumentos. Obviamente existem alguns detalhes muito originais em cada documento, a exemplo, Forlì, que contava com uma vasta experiência anterior com esse trabalho, diferente de outras realidades que elaboraram instrumentos com menos detalhamento, aproximando-se mais dos indicadores dados pelas Diretrizes ${ }^{6} . \mathrm{Ou}$ seja, existe distinção entre o instrumental utilizado na região. É possível encontrar essa documentação nas páginas web das diferentes províncias e também na página da região emiliana, por intermédio dos links relativos a cada província, com o material dos percursos realizados em cada uma. Recentemente, tivemos um encontro de tutores para projetar uma publicação em forma de livro que apresenta e discute essa trajetória. Há também publicações locais como a de Forlì. Há outra sendo preparada pelos envolvidas no processo que se desenvolveu em Piacenza, além de outras realidades locais que também publicaram suas experiências e, agora, publicaremos a experiência mais macro, referente aos aspectos do nível regional.

C. M. A experiência de Forlì se relaciona ao instrumento SPRING ${ }^{7}$, com a cirscunscrição ao segmento de 0 a 3 anos de idade?

A. G. Sim, na verdade, o percurso em nível regional também se refere exclusivamente ao segmento 0 a 3 , porque a região tem responsabilidade pelo atendimento dessa faixa etária, enquanto o atendimento para as crinaçs entre 3 e 6 anos é da federação. Contudo, posso dizer que em algumas províncias esta experiência para e com as creches influenciou o segmento da pré-escola e, portanto, em algumas províncias também foram efetivados percursos avaliativos em contextos pré-escolares a partir deste projeto referente às creches, inclusive pelo fato de alguns coordenadores pedagógicos muitas vezes terem sob sua responsabilidade essas duas etapas da educação infantil. O que tem provocado em alguns a ampliação do discurso, tanto que neste volume que publicaremos, em nível regional, nos interessa incluir essas experiências que ampliaram a discussão para o segmento 3 a 6 .

C. M. Processos de avaliação do contexto educativo, em geral, contam com a figura de um avaliador externo. No projeto do seu grupo, como se deu o exercício desse papel? Quem o assumia?

A. G. Fizemos uma escolha muito específica quanto ao profissional a ser chamado para ser o avaliador externo. Do nosso ponto de vista, o processo só

6 Ver nota de rodapé anterior (4).

7 Sobre o instrumento SPRING ver: FAEDI, Giovanni. Resenha do livro "Sguardi sul nido...". Revista Linhas, Florianópolis, v. 19, n. 40, p. 469-477, maio/ago. 2018. Traduzido por Catarina Moro. 
pode ser educativo, se for um processo verdadeiramente autoavaliativo, interessa lembrar ainda que é o grupo de trabalho (os participantes) envolvido que decide sobre como usar os resultados da avaliação. Assim, o avaliador externo entra naquele contexto; em função da auto-avaliação, o que parece um paradoxo! Mas, trata-se de um apoio para valorizar a perspectiva formativa do processo de autoavaliação; no sentido de que, obviamente, todas as autoavaliações têm o risco de uma auto-confirmação, autorreferência, então o olhar externo deve trazer uma imparcialidade, é um olhar que entra em uma dinâmica de formação em apoio ao processo de autoavaliação. Este é o pressuposto subjacente. Nas escolhas metodológicas que fizemos, em nosso sistema, o avaliador externo é ou foi coordenador de outro serviço, de outra rede municipal. Ele é o coordenador em um outro contexto; então, a intenção é criar uma dinâmica de troca, de colaboração entre estes organismos. Ele (avaliador externo) não é um perito externo, ou um engenheiro, ou um pesquisador, é um coordenador, uma coordenadora pedagógica que, por essa razão, tem consciência dos problemas de uma instituição educativa para crianças pequenas. Fizemos um curso de formação para os avaliadores externos, acerca de aspectos éticos, da necessidade de adentrar na realidade a ser avaliada com respeito e humildade... tendo pautado, também, todos os problemas que podem ser suscitados com essa presença de um profissional estranho àquela realidade. $\mathrm{O}$ avaliador externo passa, em geral, dois dias dentro da unidade, analisa os documentos, faz observações e, em seguida, faz uma reunião, um colóquio de avaliação "externa" (a partir do seu olhar), primeiro discute com o coordenador pedagógico da instituição e depois com o grupo de trabalho. Posteriormente é o grupo de trabalho que fará o balanço da experiência de auto-heteroavaliação e indicará no relatório de avaliação final as suas prioridades de intervenção nos anos seguintes. Processar e elaborar o que emergiu da auto-heteroavaliação é responsabilidade do grupo educativo, interno àquela instituição e não do avaliador externo. Falamos sobre o relatório final de avaliação como um momento de formalização de um compromisso, mas não é o avaliador externo quem diz o que deve ser feito. Ele leva e mostra o seu olhar sobre aquela realidade, pois é a nossa intenção triangular os olhares. Você tem o grupo de trabalho, em alguns casos não em todos, a equipe auxiliar também se envolve, pelo menos em parte da avaliação; por isso, tem o pessoal, o coordenador interno da instituição e o coordenador de outra instituição, no papel de avaliador externo, por isso constitui-se uma intersecção desses olhares. O diálogo criado entre esses olhares potencializa a natureza formativa da avaliação, mas sem dar maior valor ao olhar externo, ao avaliador externo, como em certos modelos, incluindo os norte-americanos. 
C. M. Nesse sentido, o avaliador externo não reporta o resultado da avaliação a nenhum outro órgão?

A. G. Reporta exclusivamente à instituição que está sendo avaliada. Com base nessa devolutiva, a instituição escreve o relatório de avaliação final que permanece dentro da instituição. No entanto, os dados que emergem do relatório de avaliação final são compartilhados também com a coordenação pedagógica da Província. A coordenação pedagógica provincial não faz nenhuma classificação, rankeamento, acerca dos dados que lhes chega, mas tem a tarefa de analisar transversalmente, em discussão com os coordenadores das várias instituições, os achados nos processos realizados em diferentes realidades e indicados nos relatórios, a fim de identificar os problemas, os aspectos críticos próprios daquela microrregião. A ideia é que a partir deste primeiro nível de avaliação da qualidade de um determinado serviço, de uma dada instituição, pode-se chegar a um nível de auto-avaliação da rede de instituições locais, identificando assim as necessidades de formação daquela microrregião. Por isso, em seguida se planejam as ações formativas, esta é uma passagem fundamental para nós, porque é sobre esta base que a coordenação pedagógica provincial faz um relatório (de segundo nível) e encaminha para a Coordenação regional e esta tem, então, um quadro geral, a título de síntese da avaliação feita nas suas diferentes províncias, o que evidencia os pontos fortes e os ponto fracos da oferta educativa na região, sem incorrer numa classificação das instituições ou das redes municipais. Com isso, a região pode promover, por exemplo, as ações de formação para as coordenadores pedagógicos das micorrregiões e dos municípios e assim por diante. Por isso, este sistema é recursivo, vai de uma instituição educativa ou município à rede provincial e para a região e, depois da região, retorna. Do nosso ponto de vista, esse é o elemento inovador e cria as condições para governar o processo numa lógica formativa. É claro que esta sistemática que nós desenvolvemos ainda requer mais experimentação. Se for assegurada em âmbito político, então haverá a possibilidade de testá-la ao longo do tempo, melhorá-la, modificá-la.

C. M. Por ser um processo com essa sistemática recursiva, envolvendo um amplo território, com muitas pronvíncias e municípios, imagino que, inclusive pela presença de um avaliador externo, seja uma ação que tenha custos. A região dispõe de orçamento para implementar essas ações? O avaliador externo recebe alguma remuneração?

A. G. Para implementarmos essa sistemática, o gasto esteve em torno de 300 mil euros. Esse valor inclui a heteroavaliação e todas as atividades relacionadas, como a formação, por exemplo. A ideia original é que a função de avaliação externa deve ser realizada periodicamente por um coordenador pedagógico de outro contexto. Isso significa que precisamos ter, de tempos em 
tempos, disponibilidade de profissionais para exercerem esta atividade, o verdadeiro problema, do ponto de vista dos custos, da sustentabilidade do sistema, está ligado ao fato de que entre os municípios existem diferenças significativas, como na razão entre o número de coordenadores por municípios. Temos que considerar também a demanda por tempo de formação para esses profissionais e para a gestão das muitas instituições... Assim, essa situação não homogênea entre os municípios impacta na viabilidade do trabalho. Se de fato queremos um sistema desse tipo, deve haver recursos financeiros específicos para desenvolvê-lo, pois não há como delegar a um coordenador pedagógico a avaliação de, por exemplo, 20 instituições. Lembrando que a avaliação seria apenas uma das atribuições do coordenador, numa lógica de intercâmbio entre serviços, em que todos se revezassem. Há um aspecto interessante... fizemos um estudo sobre a eficácia da formação e a sustentabilidade do processo, dentre outras questões, investigamos as percepções dos envolvidos e tivemos um feedback muito positivo acerca da formação dos avaliadores.

C. M. Poderia falar um pouco mais sobre a efetividade desse sistema?

A. G. Certo, essa é uma questão importante que eu gostaria de enfatizar, de início foram 104 avaliadores externos, 103 enfatizaram a formação como aspecto positivo, inclusive para eles mesmos, no sentido de que ir a outra instituição para verificar como esse outro trabalho é organizado, especialmente seguindo uma lógica de avaliação, enriquece a sua própria cultura pedagógica. De algum modo, automaticamente, quando eu avalio o outro estou, eu também estou avaliando o meu trabalho, a minha instituição. Assim, cria-se uma dinâmica interessante ao avaliador externo, que ao mesmo tempo faz reflexões também em uma perspectiva de autoavaliação em sua unidade educacional.

C. M. Poderíamos dizer que esse processo permite também uma reflexão sobre a trajetória desse profissional na Coordenação Pedagógica?

A. G. Sim, um coordenador, ao ver como o outro coordenador trabalha, poderia avaliar os instrumentos que o colega utiliza. Entre outras coisas, na região de Emilia Romagna, tivemos um projeto chamado de "Intercâmbios Pedagógicos", no qual os professores, educadores, trocavam de unidade, indo visitar diferentes instituições. A nossa ideia era valorizar essa troca no processo de avaliação, o aspecto fundamental é que este sistema deve evitar o isolamento de uma unidade educacional; porque acreditamos que esta é a pior condição em referência à possibilidade de desenvolvimento de qualidade, ou seja, isolar-se, fechar-se, não ter relação com os outros. Por isso, há uma lógica implícita nesse projeto de avaliação, que pretende criar relações entre coordenadores, entre instituições, em uma lógica de troca de rede. 
C. M. Outro aspecto relativo à efetividade do processo pode se refletir no legado formativo para as professoras e para as educadoras diretamente envolvidas com a avaliação. Vocês tiveram como ouvi-las a esse respeito?

A. G. Em verdade, quem tem relação direta com os educadores são as Coordenações. Li sobre a experiência de Bologna, da qual acompanhei uma parte, 45 relatórios de avaliação, feitos para ter retorno das dinâmicas do/no grupo. Geralmente, há uma resistência na fase inicial do processo de envolvimento do grupo de trabalho: - compartilhar os objetivos, - sensibilizar para o processo, - compartilhar o significado formativo do processo de avaliação. E podemos referir, que do ponto de vista da efetividade da formação, essa fase é fundamental. Observamos que quem cuida bem dessa fase inicial é capaz de construir um plano de participação real para o envolvimento dos educadores.

C. M. Neste projeto, o coordenador pedagógico da unidade educacional avaliada seria a figura central para a efetividade do processo?

A. G. Sim, pois é claro que este processo adentrou nas instituições de uma forma ou de outra dependendo de quanto o coordenador acreditava neste percurso. O modo de gerir o processo, fazendo ou não uma contração na temporalidade que este requer, pode fazer com que ele seja gerido superficialmente e não na profundidade que o processo requer, a depender de como o coordenador realmente faz a adesão a esse percurso. Com isso, temos trabalhado bastante com as coordenações. Mas, não há como assegurar que todas façam uma adesão de fato. O problema em processos avaliativos com o nosso tipo de abordagem, do meu ponto de vista, é também a restrição do tempo. Sobretudo quando se propõe que ele seja feito novamente, há o risco de tornar-se uma ação que se ritualiza... nessa condição, então, como você monitora esse aspecto e como consegue assegurá-lo para que a avaliação mantenha sua qualidade formativa ao longo do tempo? Esta é, obviamente, uma questão que iria surgir ao prosseguirmos com este tipo de sistema. No entanto, acredito que uma possibilidade para enfrentar esse problema é precisamente dar mais espaço aos grupos, na medida em que eles crescem, dar mais espaço para o surgimento de uma da cultura de avaliação. E, claro, ajustar os tempos de cada fase e do processo como um todo, sendo este um aspecto bastante delicado do meu ponto de vista, a fim de não ritualizar imediatamente a avaliação.

C. M. Nesse sentido, pode tornar-se algo que não tem a autenticidade esperada para promover as mudanças necessárias.

A. G. Sim, pois requer um espaço dentro da rotina cotidiana de atividades daquela instituição, requer um espaço de tempo razoável no cotidiano educativo. E também funcional na perspectiva de planejamento da formação, porque na 
nossa concepção a avaliação pode ativar melhorias, mas sobretudo perspectivar intervenções formativas e, portanto, ativar percursos para melhoria. Isto obviamente não é o retrato de um mundo feliz, porque sempre há resistências, dificuldades, tensões, instituições que ficam mais fora que dentro do processo ou fazem de conta que estão dentro dele, há toda essa amostragem de vinculação à proposição de avaliar-se.

C. M. Quando este projeto do sistema regional de avaliação iniciou?

A. G. Começamos a dialogar a respeito entre 2009/2010, o trabalho mais intensivo teve início em 2012.

C. M. Daria para se pensar numa articulação mais estreita entre avaliação e currículo nessa experiência de vocês?

A. G. Como em realidade pensamos a partir do projeto pedagógico e este nos dá as linhas pedagógicas em termos teórico e metodológico em relação a cada unidade educacional, nesse sentido entendo que também faz interface com o plano curricular, se não de forma sistemática e específica, porque a intenção era não incidir muito fortemente sobre a identidade pedagógica das instituições singularmente. Recentemente, o tema do currículo tornou-se uma problemática mais enfatizada entre nós, na Itália, decorrente da proposição da continuidade educativa 0-6, que tem influência de outros fatores, como os modelos organizacionais; o declínio da taxa de natalidade; a diminuição das matrículas em creche ( 0 a 3 anos), que pressionam politicamente para a revisão dos modelos de organização para torná-los mais flexíveis. Eu não compartilho, necessarimante, de todos as experimentções de flexibilidade de organização, alguns na minha opinião têm pouca sustentação pedagógica, mas são questões entrelaçadas à reformulação do currículo, propondo a continuidade e integração $0-6$, partindo do ponto de vista do modelo organizacional numa lógica de flexibilização. $\mathrm{Na}$ região Emilia Romagna, atualmente há municípios propondo grupamentos mistos para toda a faixa de 0-6, em Imola e, também em Parma. Algumas experiências nessa direção surgem de uma necessidade concreta, diferente, relacionada ao fechamento de turmas, ao abatimento de custos, à redução de matrículas.

C. M. Grupos mistos, que misturem bebês com crianças de até 6 anos, constituem um bom desafio...

A. G. Certamente, grupos mistos em creches, do segmento 0-3 são mais comuns, agora, as instituições e municípios que estão experimentando grupos mistos de 0-6, ao meu ver, têm que ser acompanhadas bem de perto. Como é para vocês no Brasil? 
C. M. Nas instituições públicas, estes agrupamentos mistos não são situações usuais, é bastante difícil encontrarmos. Temos instituições que atendem ambos os segmentos, ou seja, perfaz todo o 0-6, mas os agrupamentos dentro dessas instituições tendem a ser horizontais, com muita proximidade entre as idades. Grupamentos verticalizados constiuem-se um grande desafio para nós. Sobre as inovações recentes, decorrentes de demandas das realidades concretas e das alterações em dispositivos legais, quais são as suas considerações sobre o Rapporto di Autovalutazione (RAV), como proposição nacional obrigatória de autoavaliação para a Educação Infantil. Qual é sua percepção a respeito disso?

A. G. Eu tenho algumas dúvidas sobre este tipo de proposição, é um instrumento ${ }^{8}$ que será gerido por um grupo de professores que terão a função de fazer relatórios... eu realmente não vejo isso como um processo que ativa dentro da instituição um processo de confronto entre ideias dos professores, de modo colegiado. Tenho dúvidas se conseguiria suscitar um plano de reflexividade, na minha opinião o grande risco é que ele acabe tendo um uso eminentemente burocrático.

C. M. É possível que se constitua mais como um monitoramento do que uma autoavaliação?

A. G. Há no instrumento partes interessantes sobre a avaliação do contexto, ou seja, pode fazer com que as escolas concentrem a atenção em aspectos da instituição... nesse sentido, pode ser importante para evitar uma lógica de avaliação, de testagem das crianças da pré-escola, que era uma das tendências que existiam no Ministério, segundo vem sendo discutido.

C. M. Além da demanda por um tempo alargado para o desenvolvimento do processo avaliativo, quais outros pontos podem se colocar como obstáculo ou dificuldade para empreender essa abordagem de auto-heteroavaliação do sitema em nível regional?

A. G. Tivemos alguns problemas de coligação mais estreita com a liderança política, ou seja, para fazê-los compreender o significado desta operação em nível político. Creio que isso... não diria que foi um erro no nosso percurso, mas certamente foi algo para o qual não atentamos muito, por isso, corremos o risco de parecer uma ação de pedagogos para pedagogos, que criam um

8 O RAV foi publicado em 2015 e mais amplamente divulgado no início de 2016. Trata-se de uma proposição do MIUR (MIUR - Ministero dell'Istruzione, dell'Università e della Ricerca), ministério na Itália correlato ao Ministério da Educação no Brasil, de avaliação das escolas voltada a melhoria, que incluí a Educação Infantil e que se articula a uma proposição de estabelecimento de um Sistema Nacional de Avaliação italiano. 
mundo à parte e falam em "pedagogês", mas acho que este é um problema nosso, de criar a capacidade de comunicar, encontrar uma linguagem e modo de estabelecer uma conexão entre os dois mundos. Por um lado, é claro que existem profissionais da área da educação voltados para a redefinição da ideia de avaliação, para construir juntos processos verdadeiramente reflexivos, processos avaliativos que promovam reflexividade; por outro lado, há todo o âmbito político-institucional, ou seja, se você quer construir um sistema de avaliação, você tem que ser capaz de construir uma vinculação entre ambos os lados. Na minha opinião este é um aspecto decisivo. Qual seja, entender que no plano político interessa saber o ponto de vista daqueles que usufruem dos serviços, assim interessaria haver um planejamento acerca de um relato social do processo de avaliação formativa. É importante enfrentar o problema: como eu relato socialmente tudo o que eu estou fazendo para construir um serviço de qualidade? Isso também diz respeito à figura do coordenador pedagógico, porque um dos problemas da função de coordenação pedagógica é que ninguém entende bem o que uma coordenadora pedagógica faz. Faz muitas coisas, mas a percepção do exterior, daqueles que utilizam os serviços, ou de qualquer outra pessoa, é uma percepção confusa. Por exemplo, a coordenadora pedagógica de uma cooperativa onde eles fizeram a avaliação da qualidade percebida (processo do qual as famílais são os interlocutores privilegiados) em todos as instituições, no último ano, me disse uma coisa interessante: que na instituição na qual foi realizado o percurso de auto-heteroavaliação, a avaliação da qualidade percebida foi muito maior em relação a das instituições que não estavam fazendo o mesmo percurso. E isso ela relatou considerando que ainda não seria resultante do processo, porque não tinha passado muito tempo. Ainda assim, se reportava à forma como aquela unidade era capaz de comunicar às famílias que estava trabalhando na perspectiva da autoavaliação.

C. M. As famílias participam do processo de auto-heteroavaliação?

A. G. No documento relativo às Diretrizes referentes à avaliação, foi incluída a indicação de que as instituições devem fazer a avaliação da qualidade percebida pelos familiares. Deixamos a coordenação pedagógica provincial com total autonomia, pois já existiam coordenadores que trabalhavam sobre isso, de modo que eles uniram a avaliação da qualidade percebida à auto-heteroavaliação, uma vez que já era uma prática difundida. Não chegamos a realizar um trabalho em nível regional para compartilhar ou pensar em procedimentos, instrumentos e outros elementos a mais. Por ora, fez-se uma indicação e não um trabalho sistemático no nível regional. Na auto-heteroavaliação uma parcela dos indicadores diz respeito às relações com as famílias, de um ponto de vista específico, profissional, sem as famílias estarem diretamente envolvidas. 


\section{Publicações selecionadas de Antonio Gariboldi}

GARIBOLDI, A.; PUGNAGHI, A. (2017) - Analysing creative contexts in preschool settings (Early Childhood Education Beyond The Crisis. Social Justice, Solidarity and Children's Rights. - Bologna - 29 agosto -1 settembre 2017) (27th EECERA ANNUAL CONFERENCE. Social Justice, Solidarity and Children's Rights. Abstract Book.)

GARIBOLDI, A. (2017) - Educare all'aperto: creatività in gioco (- A tutta natura! Nuovi contesti formativi all'aria aperta per l'infanzia di oggi) (edizioni Junior Parma ITA) - pp. da 107 a 115 ISBN: 9788884348203

GARIBOLDI, A. (2017) - I riferimenti teorici e l'impianto metodologico del sistema di valutazione regionale (Per una qualità diffusa. La valutazione della qualità nei servizi educativi per la prima infanzia in Emilia-Romagna) (Zeroseiup Bergamo ITA) - pp. da 35 a 51 ISBN: 9788899338435

BENEDETTI, S.; GARIBOLDI, A.; MASELLI, M. (2017) - Per una qualità diffusa. La valutazione della qualità nei servizi educativi per la prima infanzia in Emilia-Romagna (Zeroseiup San Paolo d'Argon (BG) ITA) - pp. da 1 a 211 ISBN: 9788899338435

GARIBOLDI, A. (2015) - Co-costruire la valutazione: le linee guida sulla valutazione della qualità in Regione Emilia Romagna (- La valutazione di contesto nei servizi per l'infanzia italiani. Riflessioni ed esperienze) (edizioni junior Bergamo ITA) - pp. da 167 a 175 ISBN: 9788884346476

GARIBOLDI, A. (2015) - La progettazione: un approccio di ricerca (- Educare è ricerca di senso: applicazione di un approccio progettuale nell'esperienza educativa dei servizi 0-6 anni) (edizioni junior Bergamo ITA) - pp. da 19 a 25 ISBN: 9788884345974

GARIBOLDI, A.; PIA, B. M.; LARA, V. (2014) - La qualità nella scuola dell'infanzia: un percorso di valutazione formativa (Spaggiari Edizioni srl Parma ITA) - pp. da 1 a 325 ISBN: 9788884347305

GARIBOLDI, A. (2014) - Per una valutazione formativa della qualità. Significati pedagogici ed elementi metodologici (- La qualità nella scuola dell'infanzia: 
un percorso di valutazione formativa) (Spaggiari Edizioni srl Parma ITA) - pp. da 29 a 40 ISBN: 9788884347305

GARIBOLDI, A. (2013) - Il profilo professionale del coordinatore pedagogico (- Sostenere, connettere, promuovere. Il coordinatore pedagogico nei servizi educativi per l'infanzia) (Edizioni Junior Parma ITA) - pp. da 63 a 91 ISBN: 9788884346308

CARDARELLO, R.; GARIBOLDI, A. (2013) - Providing creative contexts (- Creativity in pre-school education) (SERN Bologna ITA) - pp. da 165 a 174 ISBN: . 978-8890487842

GARIBOLDI, A. (2012) - Creatività e organizzazione del contesto (- Pensare la creatività. Ricerche nei contesti educativi prescolari) (Edizioni Junior Parma ITA) - pp. da 157 a 178 ISBN: 9788884346285

GARIBOLDI, A. (2012) - Creatività e problem solving (- Pensare la creatività. Ricerche nei contesti educativi prescolari) (Edizioni Junior Parma ITA) - pp. da 133 a 146 ISBN: 9788884346285

GARIBOLDI, A.; PUGNAGHI, A. (2011) - Variabili socioculturali nei servizi educativi per l'infanzia (- Culture migranti. Luoghi fisici e mentali d'incontro) (Erickson Trento ITA) - pp. da 151 a 162 ISBN: 9788861377363

GARIBOLDI, A.; FABBRI, C.; MAURO, D. (2008) - La cosa più difficile è farlo stare in piedi. Spazi e contesti alla scuola dell'infanzia: l'esperienza Ferrarese (Edizioni Junior AZZANO SAN PAOLO (BG) ITA) - pp. da 3 a 120 ISBN: 9788884343631

GARIBOLDI, A. (2008) - Lo spazio e la sua organizzazione (- Tempi, spazi, raggruppamenti. Un dispositivo di analisi e valutazione dell'organizzazione pedagogica della scuola dell'infanzia) (Edizioni Junior AZZANO SAN PAOLO (BG) ITA) - pp. da 77 a 93 ISBN: 9788884343887

GARIBOLDI, A. (2007) - Valutare il curricolo implicito nella scuola dell'infanzia (Edizioni Junior AZZANO SAN PAOLO (BG) ITA) - pp. da 1 a 185 ISBN: 978888434381X ISSN: - [Monografia o trattato scientifico (276) Monografia/Trattato scientifico] 
GARIBOLDI, A. (2006) - Pedagogia latente e ricerca educativa (- Fare ricerca in Pedagogia. Saggi per Egle Becchi) (Franco Angeli Milano ITA) - pp. da 243 a 247 ISBN: 8846479424

GARIBOLDI, A. (2002) - I tempi quotidiani nella scuola dell'infanzia: le forme della socialità (- Il tempo nella quotidianità infantile) (Edizioni Junior AZZANO SAN PAOLO (BG) ITA) - pp. da 85 a 90 ISBN: 9788884340979

GARIBOLDI, A. (2002) - La vita quotidiana al nido: tempi e spazi della quotidianità. Arredi e materiali. (- Idee guida del nido d'infanzia) (edizioni Junior AZZANO SAN PAOLO (BG) ITA) - pp. da 26 a 30 ISBN: 9788884341358

GARIBOLDI, A. (2001) - AVSI. Item A1.4, A1.5, D4.15 e Sottoscala A4 (- AVSI. Autovalutazione della scuola dell 'infanzia) (CEDE-Franco Angeli ROMA-MILANO ITA)

GARIBOLDI, A. (2001) - Modelli educativi e scale di valutazione della qualità (- AVSI. Autovalutazione della scuola dell'infanzia) (Cede-Franco Angeli ROMA-MILANO ITA) - pp. da 263 a 270 ISBN: 9788846429926

GARIBOLDI, A. (2000) - La valutazione della qualità del contesto educativo nella scuola dell'infanzia: l'uso della SOVASI come strumento di formazione e di ricerca (- Manuale di valutazione del contesto educativo) (Franco Angeli MILANO ITA) - pp. da 275 a 288 ISBN: 9788846419125

GARIBOLDI, A. (2000) - Un'esperienza di valutazione formativa negli asili nido di Ferrara (- La qualità negoziata. Gli indicatori per i nidi della Regione Emilia Romagna) (edizioni Junior AZZANO SAN PAOLO (BG) ITA) - pp. da 147 a 152 ISBN: 9788884340009

GARIBOLDI, A. (2000) - Valutare e riflettere (- Uno o più nidi) (edizioni Junior AZZANO SAN PAOLO (BG) ITA) - pp. da 217 a 222 ISBN: 9788884340085

GARIBOLDI, A. (1997) - La giornata educativa in una scuola dell'infanzia (Valutare e valutarsi) (Edizioni Junior AZZANO SAN PAOLO (BG) ITA) - pp. da 41 a 54 ISBN: 9788886858113

GARIBOLDI, A. (1997) - Le modalità del fare educativo: l'attività negoziata (- Valutare e valutarsi) (Edizioni Junior AZZANO SAN PAOLO (BG) ITA) pp. da 77 a 88 ISBN: 9788886858113 
BONDIOLI, A.; FERRARI, M.; GARIBOLDI, A. (1995) - La giornata educativa: elementi di analisi (- Manuale della scuola del bambino dai tre ai sei anni) (Franco Angeli MILANO ITA) - pp. da 36 a 74 ISBN: 9788820489267

GARIBOLDI, A. (1994) - La scuola dell'infanzia pubblica nella provincia di Pavia: valutazione della qualità dell'ambiente educativo secondo la SOVASI (- SOVASI - Scala per l'osservazione e la valutazione nella scuola dell'infanzia) (Edizioni Junior AZZANO SAN PAOLO (BG) ITA) - pp. da 78 a 93 ISBN: 9788886277358

GARIBOLDI, A.; LIVRAGHI, P. (1994) - Un esempio di ricerca valutativa nelle scuole dell'infanzia (- La valutazione di contesti prescolari: strumenti e realtà) (Edizioni Junior AZZANO SAN PAOLO (BG) ITA) - pp. da 46 a 62 ISBN: 9788886277297

GARIBOLDI, A. (1993) - Recensione libro: SVANI (Scala per la Valutazione dell'Asilo Nido) (- Scala per la valutazione dell'asilo nido) - BAMBINI - n. volume 3 - pp. da 90 a 91 ISSN: 0393-4209

FEIN, G.; GARIBOLDI, A.; BONI, R. (1993) - The Adjustment of Infants and Toddlers to Group Care: The First 6 Months (Ablex Publishing Corporation:355 Chestnut Street:Norwood, NJ 07648:(973)767-8450, (201)767-8455 (Customer Service), INTERNET: http://www.jaipress.com, Fax: (973)767-6717) - EARLY CHILDHOOD RESEARCH QUARTERLY - n. volume 8 - pp. da 1 a 14 ISSN: 0885-2006

GARIBOLDI, A.; LIVRAGHI, P. (1992) - La qualità del nido (Edizioni Junior:Via delle Industrie S N, I 24052 Azzano San Paolo Italy:011 39035 534123, EMAIL: ce@edizionijunior.it, Fax: 01139035 534143. Editore precedente:Publisher Juvenilia Ed) - BAMBINI - n. volume 2 - pp. da 23 a 31 ISSN: 0393-4209

\section{Publicações de Antonio GARIBOLDI no Brasil}

GARIBOLDI, A.; MASELLI, M. Construindo a avaliação em conjunto: a experimentação de uma abordagem participativa para avaliação na região italiana 
da Emília Romanha. Pro-Posições [online], 2018, v. 29, n. 2, p.46-71. http:// www.scielo.br/pdf/pp/v29n2/0103-7307-pp-29-2-0046.pdf

GARIBOLDI, A.; PUGNAGHI, A. Relação educativa, avaliação e trabalho de equipe. Revista Linhas. Florianópolis, v. 19, n. 40, p. 94-115, maio/ago. 2018. Título original: Relazione educativa, valutazione e lavoro di equipe. Traduzido por Fernando Coelho, com revisão técnica de Catarina Moro. http://www. revistas.udesc.br/index.php/linhas/article/viewFile/1984723819402018094/pdf

GARIBOLDI, A. (2004) Os Tempos Cotidianos na Pré-escola: as formas da sociabilidade. In: Bondioli, A. O Tempo no Cotidiano Infantil. São Paulo: Cortez, pp. 97-103.

GARIBOLDI, A. (2003) O dia-a-dia educativo em uma pré-escola. In: BECCHI, E.; BONDIOLI, A. (Orgs.). Avaliando a pré-escola. Campinas: Autores Associados, pp. 37-56.

\section{REFERÊNCIAS}

FAEDI, Giovanni. Resenha do livro "Sguardi sul nido...". Revista Linhas, Florianópolis, v. 19 , n. 40, p. 469-477, maio/ago. 2018. Traduzido por Catarina Moro.

MORO, Catarina. Diferentes olhares para a creche: a avaliação de contexto com o instrumento SPRING em um município da Emilia Romagna. Revista Linhas. Florianópolis, v. 19, n. 40, p. 138-160, maio/ago. 2018. Disponível em: http://dx.doi. org/10.5965/1984723819402018138

Texto recebido em 14 de maio de 2018. Texto aprovado em 09 de dezembro de 2018. 